\title{
LA PROPIEDAD Y LAS COMUNIDADES INDÍGENAS EN MÉXICO
}

\section{Óscar Correas}

CEIICH-UNAM

\begin{abstract}
RESUMEN
El estudio de las comunidades indígenas en la búsqueda de la descripción de sus sistemas normativos, en México, al menos, muestra que el tema de la propiedad es central para entender el contenido de estos sistemas. El pensamiento antropológico, en cambio, dejando de lado la estructura social, en este caso la no propiedad sobre la tierra, quiere encontrar la explicación de la normatividad propia de esas comunidades en el sentimiento de pertenencia a la comunidad. El análisis de las normas relacionadas con el control sobre la tierra muestra que ese sentimiento comunitario tiene que ser explicado al mismo tiempo, y eso solo puede hacerse a partir del estudio de las relaciones sociales propias de una sociedad agraria no capitalista. Por otra parte, no cabe dejar de decirse que el contenido de la normatividad comunitaria es lo que explica la pervivencia de la comunidad, y de igual manera explica la terquedad y la fuerza conque los sabios de esas sociedades insisten en la conservación de su modo de vida —es decir, de sus normas- para reproducirse como comunidades que intentan pervivir al margen de la sociedad capitalista, a la cual ven como enemiga de esa pervivencia. En suma, la propuesta dice: no se puede explicar el contenido de las normas observadas en las comunidades sin recurrir a las formas de control sobre la tierra. La actitud comunitaria, ese sentimiento de pertenencia, es una necesidad en orden con la reproducción de su vida, determinada primordialmente por el control sobre la tierra.
\end{abstract}

Palabras clave: Antropología jurídica, derecho de propiedad, propiedad agraria, comunidad indígena, familia ampliada. 


\begin{abstract}
The study of indigenous communities in the search to describe their normative systems, in Mexico at least, illustrates that the issue of property is central to understanding the content of these systems. Anthropological thought, on the other hand, leaving aside social structure, in this case non-ownership of land, wants to find the explanation of the particular type of regulation of these communities in "the sense of community belonging." Analysis of the norms related to control over land illustrates that this community feeling must be explained at the same time, and that can only be done based on study of the particular social relations of a non-capitalist agrarian society. On the other hand, it cannot be emphasized enough that the content of community regulatory norms is what explains the survival of the community, and in the same manner explains the stubbornness and strength with which the wise persons of these societies insist on conserving their way of life - in other words, their norms - to reproduce themselves as communities intending to survive outside capitalist society, which they see as an enemy to that survival. In summary, the proposal states that the content of the norms observed in these communities cannot be explained without addressing the forms of control over land. The community attitude, that sense of belonging, is a necessity for the reproduction of their lives, primarily determined by control over land.
\end{abstract}

Key words: Legal anthropology, property rights, agrarian property, indigenous community, extended family 


\section{INTRODUCCIÓN}

El estudio de las sociedades indígenas, en México, ha venido siendo asunto casi exclusivo de la Antropología, sea cultivada por antropólogos, sea cultivada por otros científicos sociales como los sociólogos. Sólo desde hace muy poco tiempo, los pueblos indígenas han llamado la atención de los juristas. Y no es que éstos desconocieran la existencia de esos pueblos, sino que su interés se había venido centrando exclusivamente en la resolución de los problemas normativos que hacen presente estas sociedades, en su enfrentamiento con la sociedad capitalista dominante. Era, pues, una mirada estrictamente jurídica, que intentaba responder a la pregunta: ¿cómo deben ser las reformas jurídicas necesarias para atender $-\mathrm{o}$ rechazar, pues muchos juristas a eso se han dedicado- las demandas de los pueblos indios.

Pero, desde hace algún tiempo, los —algunos— juristas nos hemos acercado al «tema» — maravillas del lenguaje: nuestro mundo mira al mundo indígena como «tema», si no es que como «cuestión»— indígena, de otra manera. En primer lugar, hay una nueva actitud en la mirada de los juristas: ya no se trata de fagocitar a las comunidades indígenas, sino de construir su autonomía, con ellos y no para ellos. La actitud ha cambiado. En segundo lugar, ya no se trata sólo de estudiar cómo resolver al «problema» desde el punto de vista del derecho hegemónico, sino de estudiar los sistemas normativos que estos pueblos usan para regir su pervivencia y sus conflictos. La idea es: para proponer soluciones, en el marco del derecho hegemónico, se requiere conocer los sistemas normativos alternativos y sus fundamentos; sus fundamentos entendidos como las estructuras sociales, y sus fundamentos ideológicos.

Este ingreso de los juristas a un trabajo hecho hasta ahora por antropólogos, ha mostrado que éstos últimos, desde el punto de vista de la Teoría del Derecho, han venido trabajando con conceptos pobres, a veces auténticas ideologías, que han puesto problemas a los juristas interesados. Por ejemplo, los antropólogos han venido hablando de las «costumbres» como si ésta fueran «prácticas» —repetidas, dicen. Y no es así: las costumbres son normas y no 
prácticas. Lo que sucede es que esas normas deben inducirse de la observación de las conductas comunitarias. Igualmente sucede con la dificultad para aceptar que las comunidades disponen de sistemas normativos y no de «usos y costumbres», es decir, normas, a las que ven como sueltas, dispersas, como no integrando un sistema. Esto último, es decir, la expresión «usos y costumbres» no es un concepto teórico sino una ideología racista, que supone a los pueblos indios como no suficientemente humanizados como para tener un sistema jurídico propio. También ha sido difícil el diálogo interprofesional porque los estudios antropológicos no son estrictos en su mirada de los sistemas alternativos. Es decir, hay resistencia a comprender que se trata de sistemas jurídicos alternativos, que son distintos, autónomos. Y si no se tiene en cuenta este tema propio de la Teoría del Derecho, el tema de los sistemas normativos, se produce gran confusión cuando se trata de estudiar la normatividad de una sociedad indígena. Esto sucede, porque, en esas comunidades, además de las normas de sus propios sistemas, suelen ser efectivas también algunas normas del sistema jurídico hegemónico. Y si no hay un claro entendimiento de que se trata de sistemas jurídico alternativos, es decir, distintos, se pierde la posibilidad de capturar el grado de independencia de las comunidades, tanto como el grado de agresión que sufren por parte de la sociedad capitalista y sus funcionarios. Dicho de otra manera: si se investiga cuáles son las normas vigentes en una comunidad, y se toman indistintamente las normas de la comunidad, junto a otras normas que no son de la comunidad, y se las revuelve, se pierde la posibilidad de saber cuáles son unas y otras, puesto que se las ha considerado previamente como de la misma clase; y no es así, puesto que son normas de dos sistemas normativos distintos. Y eso último, sólo es posible advertirlo si se cuenta con una teoría plausible de los sistemas normativos.

Otro tema que hace dificultoso el aprovechamiento del trabajo anterior de los antropólogos, por parte de los juristas, es precisamente el de la propiedad. Se carece de un concepto teórico que permita un análisis certero de los fundamentos de la comunidad. Así, resulta difícil entender el sentimiento comunitario, sin entender que éste es un sentimiento generado por un control sobre la tierra, que no es estrictamente una forma de propiedad; es, más bien, una forma de no propiedad. 
Lo que finalmente, puede decirse, es que la participación de los juristas aporta, al estudio de las comunidades indígenas, el punto de vista, y los conceptos, de la Teoría General del Derecho. Todo eso, sin que deba dejar de decirse que tampoco todos los juristas usan, o conocen, esta teoría. Problema con el que tropieza todo profesor de Filosofía del Derecho, aún a esta altura del gran desarrollo de esa teoría.

\section{HACIA UNA DEFINICIÓN DEL CONCEPTO DE COMUNIDAD}

Lo primero que cabe preguntarse, es si los pueblos indios constituyen, o no, comunidades. Porque, ya a primera vista, se comprende que las conclusiones que a que pueda llegarse, varían según sea la respuesta. Ahora bien, para decidir esto, es decir, si son, o no, comunidades, es necesario disponer de un concepto teórico de comunidad. Mi propuesta es, en este sentido, reservar el uso de la palabra «comunidad» para referir ciertas sociedades que se caracterizan por los siguientes elementos.

\section{LA NO PROPIEDAD PRIVADA DE LA TIERRA}

Sin perjuicio de que «propiedad» debe ser definido, como haremos más adelantes, puede decirse aquí que las comunidades se caracterizan por realizar un control de la tierra que no es, estrictamente, propiedad.

\section{LA EXISTENCIA DE LA FAMILIA AMPLIADA}

Las comunidades se organizan en familias «ampliadas». Esta idea pertenece íntegramente a la teoría antropológica, y de ella habría que tomarla. Cabe decir, no obstante, que se puede avanzar diciendo que la familia ampliada difiere de nuestra familia nuclear, por estar integrada por un número grande — también incierto — de integrantes, comandados por un patriarca, que puede pensarse, tal vez, con nuestra figura del abuelo. De modo que los hijos, los hermanos, los tíos, los primos, integran la familia, y desarrollan fuertes vínculos ideológicos. 
Por lo demás, estas relaciones familiares constituyen las relaciones sociales de producción, pues es la forma, ideológica, en que se organizan los miembros de la familia, para acceder a la producción agraria.

Vale decir que los juristas conocemos este tipo de familia, por los estudios de Derecho Romano: la familia ampliada es la vieja Gens romana, la que constituía la organización social de base en los primitivos tiempos en que Roma aún no se había convertido en una sociedad mercantil — cosa que sucedió hacia el siglo II antes de nuestra era. Buena parte de las normas de aquella sociedad, se encuentran en las comunidades indígenas organizada en familias ampliadas.

\section{LA PRODUCCIÓN AGRARIA PARA EL CONSUMO}

La producción agraria de las comunidades, se hace para el consumo, no para la venta. Es decir, no son sociedades mercantiles. Cada miembro de la familia, que dispone de una parcela cedida, y controlada, por el patriarca, produce para el consumo de su familia nuclear. Esta producción es, principalmente, maíz.

Lo anterior no quiere decir que no haya otros cultivos, que producen para la venta, como el café por ejemplo, en buena parte de las zonas montañosas del sur y centro de México. Igualmente puede haber producción de aves, bovina, ovina o porcina, que tenga, en parte, un destino mercantil, fuera de la comunidad.

El grado en que estos tres elementos se conserven en una sociedad indígena, permite conocer, o hacer hipótesis, si se quiere ser más prudente, el grado de penetración agresión-, a que son sometidas esas sociedades. Por ejemplo, la desobediencia a las normas que prohíben vender la tierra, muestran un grado importante de disolución de las relaciones comunales. Y aquí se puede comprender la importancia del aporte de la Teoría del Derecho en los trabajos antropológicos. En efecto, el concepto de norma costumbre- permite ver la venta de la tierra como desobediencia de normas, y no como expresión de normas. Sin el concepto de norma, y de efectividad de las normas, la venta de 
la tierra no consigue comprenderse, pues hay quienes no venden. Entonces, ¿cuál es la norma de la comunidad? ¿La que permite vender o la que lo prohíbe? Sin el concepto de norma no se puede responder a esta pregunta. Que conlleva una cuestión central: ¿es una comunidad, una sociedad en la que se vende la tierra? Depende: como se trata de la desobediencia a la norma prohibitiva, es necesario hacer una reflexión acerca del número de las desobediencias. Porque una desobediencia amplia, generalizada, muestra, más bien, una norma en camino de desaparición; y, por tanto, a una sociedad en camino a la mercantilización. Esto es directamente extraído de la Teoría del Derecho, específicamente de Kelsen, para quien las normas son válidas únicamente si tienen cierto grado de efectividad.

\section{EL CONCEPTO DE PROPIEDAD}

La palabra «propiedad», en castellano, es muy confusa, polisémica. Con ella referimos la cosa objeto del derecho a la propiedad; como cuando decimos «alguien ha dañado mi propiedad» - lo cual no puede querer decir que «alguien ha dañado mi derecho a la propiedad». Ahora bien, el derecho civil es el encargado de establecer las normas generales acerca de lo que llamamos, precisamente, «propiedad». Los códigos civiles, para decir lo que la propiedad es, han seguido cuando menos estos dos caminos: algunos códigos definen la propiedad, y otros no la definen, pero establecer las normas que se aplican a esto llamado «propiedad». Por ejemplo, el código Civil para el Distrito Federal, en México, dice:

El propietario de una cosa puede gozar y disponer de ella con las limitaciones y modificaciones que fijen las leyes (art. 839). La propiedad no puede ser ocupada contra la voluntad de su dueño, sino por causa de utilidad pública (art. 831).

Pero, como se ve, este código no da una definición de «propiedad. Más bien se refiere a lo que el propietario puede hacer con su propiedad —aquí en el sentido de «cosa»: puede gozar y disponer de ella, y oponerse a que sea ocupada en contra de su voluntad. Las definiciones, en el Derecho civil mexicano, corren por cuenta de la doctrina. Por ejemplo, 
para un autor, la propiedad — en tanto derecho a - es El poder jurídico que una persona ejerce en forma directa e inmediata sobre una cosa que aprovecharía totalmente en sentido jurídico, siendo oponible este poder a un sujeto pasivo universal, por virtud de una relación que se origina entre el titular y dicho objeto. ${ }^{1}$

Obsérvese en esta definición doctrinaria, una confusión notable, y frecuente, entre los juristas: confunden las relaciones entre los individuos con relaciones entre éstos y los objetos inertes. Si hay algo que pueda ser una relación «de propiedad» tiene que ser una relación entre seres humanos, aún cuando sea con motivo de las cosas. Pero tratándose de normas, y el derecho es eso, no cabe hablar de relaciones entre seres humanos y cosas; solamente cabe hablar de relaciones entre actores sociales. Y esto es de la mayor importancia, pues una teoría de la propiedad requiere aprehender correctamente esto: la propiedad es una relación social, y, obviamente, entre actores sociales.

Otros códigos, adoptaron otra estrategia: definir la propiedad en el cuerpo normativo, dejando a los juristas, solamente su comentario. Por ejemplo, el código argentino, el antiguo y el nuevo, dice:

El dominio es el derecho real en virtud del cual una cosa se encuentra sometida a la voluntad y a la acción de una persona (art. 2506).

El autor de este código, Dalmacio Vélez Sársfield, le puso notas a muchos de sus artículos. En este caso, anotó:

La L. 1, Tít. 28, Part. $3^{\text {a }}$, define el dominio o la propiedad: poder que ome ha en su cosa de facer de ella o en ella lo que quisiere, según Dios o según fuero. [...] El Cód. Francés, art. 544, define la propiedad diciendo que: «la propiedad es el derecho de gozar y de disponer de las cosas de la manera más absoluta». Este artículo, en lugar de dar una verdadera definición, hace más bien, por una enumeración de los principales atributos de la propiedad, una descripción de ese 
derecho. ${ }^{2}$ Los romanos hacían una definición empírica de la propiedad, jus utendi et abutendi, definición que no tiene relación sino con los efectos y no con las causas, ni con los orígenes, porque ellos debían ocultar los orígenes de sus propiedades. ${ }^{3}$

Como se ve, sea con una u otra estrategia, el derecho civil, y los civilistas, dan vueltas alrededor de las mismas ideas. La propiedad 1) es una relación persona-cosa; 2) permite «gozar» de las cosas; 3) la cosa está «sujeta» a la voluntad del propietario.

Pero por ningún lado aparece el verdadero asunto: la circulación mercantil. La propiedad de la que hablan, el código civil, y los juristas, es una que protege la circulación mercantil. No se trata del goce de las cosas, sino de que se puedan vender: «están sujetas a la voluntad del propietario». Si hay algo así llamado en el derecho civil, es porque las cosas se pueden vender. Lo que se protege no es, en realidad el «goce», sino la calidad mercantil de las cosas. ${ }^{4} \mathrm{Si}$ el derecho tuviera algún interés en el «goce» por parte de la gente, muy otras serían las normas. La verdad es que todo lo que viene después de estos artículos definitorios, es un largo discurso que protege la posibilidad de que las cosas circulen en el torrente mercantil. Y, con ello, es mucho más curiosa esta idea de que la propiedad relaciona las cosas con las personas. No. Relaciona a los individuos, vueltos «personas», entre ellos. Porque la mercancía es una relación social. Y las cosas, en el derecho civil, son los objetos que tienen un valor, esto es, un valor de cambio.

Interesa subrayar la constancia con que los juristas ligan la idea de «propiedad», con la de «voluntad». Como se sabe, nadie sabe qué sea eso, aunque todos creemos experimentarlo. Pero, ¿por qué un discurso tan importante como el del Derecho recurre a palabras tan etéreas como «voluntad»? Por otra parte, los juristas no definen que es la voluntad, sino que usan normas que dicen cuándo no hay voluntad. Parece obvio: si nadie sabe qué es la voluntad, no hay cómo el Derecho pueda definirla; luego entonces, hay que establecer cuándo no hay voluntad. 
Pero la idea de voluntad, por otra parte, no es patrimonio del mundo antiguo. La idea del destino excluye totalmente la posibilidad de la voluntad. Que es, por tanto, una idea moderna, aportada por el cristianismo: si no hay voluntad, y libre, no hay pecado. Tampoco delito. Y tampoco contratos. Y hé aquí la cuestión: la propiedad está ligada, o sometida, a la voluntad, porque la propiedad es la ocasión de los contratos; los contratos, es decir, la circulación mercantil, requieren la propiedad, sometida a la voluntad. Existe algo llamado «propiedad», porque la sociedad mercantil requiere cambiar; requiere que el portador de la mercancía —el «propietario»— pueda llevarla al mercado, y dejarla ir, al mismo tiempo que percibe el precio, o contravalor equivalente.

Lo que permite todo lo anterior, es precisamente esta idea, tan confusa, de la voluntad. Y, como se verá, nada de esto existe en la comunidad indígena — si se mantiene como tal.

Por otra parte, esto no ha sido siempre así. La propiedad, como calidad mercantil de las cosas, es propia de las sociedades mercantiles — siendo el capitalismo una de ellas. En la Historia del Derecho se comprueba fácilmente este aserto. Especialmente en la del Derecho Romano: pasaron varios siglos antes de que los juristas hablaran de propiedad en el sentido en que hoy hablan los juristas. En los tiempos premercantiles, en Roma no había realmente propiedad, porque las cosas no se vendían. Pero, en la medida en que la mercancía se fue apoderando de aquella sociedad agraria antigua, los juristas fueron encontrando, poco a poco, estrategias lingüísticas que permitían vender cosas que antes era prohibido vender. Este proceso se cumplió alrededor del siglo II antes de nuestra era. A partir de entonces, el Derecho Romano se convirtió en un derecho propio de una sociedad mercantil. Y, después de la caída del imperio de Occidente, y al final de la Edad Media, los juristas ya modernos, encontraron en aquel Derecho Romano, las normas que convenían a la naciente sociedad burguesa: la sociedad mercantil.

Lo anterior es importante, porque hay que contestar esta pregunta: ¿qué queremos decir cuando decimos que en una sociedad hay «propiedad»? Podemos contestar diciendo que la hay cuando se excluye a alguien, o todos los demás, del control de una cosa -o una parcela. 
Pero con ello no diríamos nada interesante, porque en toda sociedad conocida hay excluidos. En las sociedades más antiguas, los excluidos son los miembros de otras familias, tribus o clanes. En el mundo mercantil, los excluidos son todos los demás miembros de la sociedad.

Podemos decir que «propiedad» significa el control productivo; esto es, la exclusión de otros del uso de las cosas, la tierra principalmente, para la producción agraria. Esto significaría, simplemente, que las normas establecen cuáles miembros de la sociedad pueden producir en la parcela.

Podríamos decir que tiene la propiedad, o la apropiación de las cosas y la tierra, quien domina el proceso de producción por sí mismo, sin ser explotado por otros.

Entonces, ¿a qué le llamaremos «propiedad»? Parece plausible reservar el uso de esta palabra, para todos los fenómenos que podemos llamar de «derecho a» la propiedad de las cosas. «Derecho a», significa que no se trata de una relación persona-cosa, sino de una relación social, creada y protegida por el Derecho, por las normas.¿Qué se protege? La seguridad mercantil. La sociedad mercantil es una en la cual circulan mercancías y contracircula el dinero. Y para que esto «funciones», es decir, para que se reproduzca la circulación permanentemente, se debe garantizar que quien lleva una cosa al mercado, sea quien es socialmente reconocido como quien «debe» llevarla. O, dicho de otra manera, el Derecho Civil dice, con claridad, quién será reconocido socialmente, como quien puede llevar la mercancía para su venta.

Si reservamos, entonces, la palabra «propiedad» para los fenómenos modernos de la sociedad mercantil, toda otra relación no es propiedad. Es más, no tiene sentido preguntar por la propiedad en una sociedad no mercantil. Por más que se vean fenómenos de exclusión. 
Por último, vale la pregunta. Este fenómeno esencial de la propiedad, tanto como de la no propiedad, ¿tiene alguna importancia en las construcciones ideológicas de una sociedad? Si respondemos que no, deja de tener importancia el estudio de la no propiedad en las comunidades indígenas. $\mathrm{Y}$ habría que decir que, en nuestra sociedad, no tiene ninguna consecuencia ideológica que todo sea mercancía, y que en la circulación mercantil se arroje valor para obtener un mayor valor. Por ejemplo, habría que decir que el individualismo egoísta no tiene nada qué ver con la mercantilización de toda la vida social. En verdad, quien diga esto último, no debería ser tomado sino como un panegirista de la sociedad capitalista.

Si respondemos que la propiedad, y la no propiedad, sí tienen qué ver con las formas ideológicas de una sociedad, vale preguntarse cuáles son las relaciones entre el control de las cosas, especialmente la tierra, y la visión del mundo.

\section{PROPIEDAD VERSUS CONTROL DE LA TIERRA}

Lo que se observa - los propios antropólogos lo han hecho-, es que en las comunidades indígenas — las que son comunidades conforme con la definición propuesta más arriba—, existe un férreo control sobre la tierra. «Férreo», metáfora para decir que las normas son estrictas y prometen las peores sanciones —el escarnio público-, a quienes incumplan las normas relativas a las relaciones sociales de producción. Y las relaciones sociales con motivo de la producción, son relaciones de control sobre la tierra — principalmente, pero no únicamente.

Pero por ninguna parte aparece la idea de que la tierra, y los instrumentos de labranza, pueden venderse. Por tanto, no hay propiedad. Cuando estas ideas aparecen, la comunidad ha comenzado a disolverse y a ser fagocitada por la sociedad capitalista circundante. Las ventas de tierra son incumplimiento de normas, no normas que conviven con las otras. $\mathrm{Y}$ ésta es una cuestión que debe resolverse utilizando una plausible Teoría del Derecho, especialmente una Teoría de los sistemas normativos. Pues si se mira «los hechos», o sea 
las ventas de tierras - ya vimos que los antropólogos dicen que las costumbres con conductas reiteradas - como obediencia de normas, entonces resulta que la comunidad tiene normas obviamente contradictorias: normas que prohíben la venta de la tierra, y normas que la permiten. Lo cual es un disparate. Además de una grosería para con las sociedades indígenas, que son hechas aparecer como sociedades incapaces de distinguir contradicciones normativas.

Nada de eso: las violaciones a las normas de control sobre la tierra, son eso: desobediencias. Y claro que el camino de la inefectividad de las normas, conduce a la desaparición de las sociedades. Por eso, el grado de esta inefectividad normativa, permite hacer buenas hipótesis sobre el grado de agresión que sufren las comunidades. Y es la no propiedad sobre la tierra, lo que permite hablar de esa agresión: en la medida en que la no propiedad cede terreno a la propiedad del Derecho Civil, la comunidad comienza a desaparecer.

\section{LA IDENTIDAD COMUNITARIA Y EL CONTROL SOBRE LA TIERRA}

La comunidad, entonces, se define, en primer lugar, por la no propiedad sobre la tierra pero no solamente de la tierra-. En segundo lugar, se define por las relaciones de producción, que son las relaciones «familiares». El acceso al uso de parcelas, está controlado por la familia, en la cual la figura del patriarca es evidente, e imprescindible. Las relaciones familiares, pero de la familia ampliada, son las relaciones de producción agraria. Y el derecho protege estas relaciones con normas cuya desobediencia es sancionada de las peores maneras. En tercer lugar, el destino de la producción es el autoconsumo: los comuneros, en primer lugar, producen, no para llevar al mercado, sino para consumir.

Ahora bien, esta sociedad, que así produce, no puede subsistir, reproducirse, sin una ideología especial. Y aquí «ideología» no se distingue de normatividad. Y esto sucede en todas las sociedades conocidas: la ideología — visiones del mundo, imaginario social, 
simbolismos, sentimientos- constituye el discurso propio de las relaciones sociales de producción. El discurso «habla» de esas relaciones. Y las pone como valiosas. La tierra aparece como teniendo vida humana que debe ser respetada. El discurso habla de la necesidad de que la familia se mantenga «unida»-que se obedezca al patriarca y se respete a los mayores, los sabios. Esta unidad aparece como valiosa, en el sentido de «buena», pero también «bella». El discurso repite constantemente la idea de que cada comunero es responsable por toda la familia, y por toda la comunidad. También la idea del desamparo en que quedaría alguien que no amara y obedeciera la normatividad familiar y comunal. La familia ampara, jamás deja a algún miembro en la soledad, y reclama obediencia, pero no por el temor. En esto consiste el sentimiento "de pertenencia" propio de las comunidades, cuyo fondo es la no propiedad de la tierra, pero su control por parte de la familia.

El discurso habla también de la comunidad de familias. De la necesidad de permanecer unidos — esto es, de obedecer las normas, las antiguas, y las que produce la asamblea en la cual se oye, en primer lugar, la palabra de los mayores, los sabios. La comunidad en conjunto, repite las bondades de la familia: amparo, jamás dejar a alguien «afuera». Y a cambio, reclama obediencia, pero sin temor. El discurso transmite la idea - los sentimientos - de que, fuera de la comunidad, existe lo otro, duro, peligroso. El discurso genera el sentimiento de amor a esta representación de lo colectivo, que son los momentos de intercambio discursivo, como las fiestas, actos especiales, edificios, arte. Todo montado en la conciencia de que la tierra es el origen de toda la vida social; que debe cuidarse como a los seres humanos, delicadamente. Todo lo cual no podría suceder en una sociedad mercantil.

\section{LA NORMATIVIDAD COMUNITARIA}

La propuesta es que toda la vida de la comunidad, debe interpretarse como el cuidado de lo colectivo, del "nosotros", que es sugerido por la necesidad de las relaciones sociales con motivo del control sobre la tierra. Y que todas estas relaciones sociales, y sus 
representaciones discursivas, consiguen reproducirse por la obediencia a las normas de la comunidad. Y que el contenido de las normas está determinado por la necesidad de reproducir la misma vida agraria, fincada en el control de la tierra que excluye, a las otras familias de la tierra familiar, y a todos los "otros" extraños a la comunidad de la tierra de toda la comunidad. Las normas cuentas, además de su propio sentido deóntico, con un apoyo ideológico fundamental: el otro debe estar excluido de la posibilidad de acceder a la tierra.

La normatividad comunitaria, entonces, pone como obligatorias las conductas que permiten la reproducción social. Y, como prohibidas, las conductas que son vistas como contradictorias respecto de las primeras. «Son vistas», pues sucede a menudo que, cuando «miramos» algunas de esas conductas, no se nos aparecen como conductas que realmente ayuden a la reproducción, o que «realmente« atenten contra la reproducción. Pero eso sucede simplemente porque somos habitantes de otras relaciones sociales. Relaciones en las cuales, la causalidad que llamamos «científica», determina nuestra manera de ver el mundo -una manera positivista, sin duda-, porque la nuestra es una sociedad capitalista, asentada en el principio de la eficacia productiva: entre nosotros a nadie se le ocurre pensar que alguna fiesta, o rezo, tendrá alguna relación con la cantidad de automóviles que producirá una fábrica, o la ganancia que obtendrá el dueño de ese capital. Porque nada depende de la colectividad, sino de la suerte y la laboriosidad individual. Ningún atisbo de alguna superioridad de nuestra sociedad. Todo lo contrario.

Las normas fundamentales de la comunidad son:

1) Prohibido enajenar la tierra, por cualquier título o motivo.

2) Obligatorio obedecer a la familia, en la voz del patriarca.

3) Prohibido enajenar la cosecha principal —maíz, frijol.

4) Obligatorio participar en el gobierno de la comunidad.

O sea, nada de propiedad o derecho a la propiedad. Al contrario: toda la normatividad, está encaminada a impedir que exista la propiedad privada de la tierra. Y, por el otro lado, el 
entero conjunto de las normas comunitarias, su contenido, se explica por esta necesidad de impedir el control individual sobre la tierra; impedir la venta de la tierra.

Lo anterior puede mantenerse como hipótesis plausible. Pero quienes han estudiado a las comunidades, informan, sin lugar a dudas, de que de esto se trata: mantener a la comunidad, y la comunidad se mantiene únicamente si existe control colectivo sobre la tierra.

\section{LA LUCHA POR LA PERVIVENCIA DE LA COMUNIDAD}

Lo anterior, explica, por lo demás, el sentido de la lucha de las comunidades por permanecer como tales. Explica lo que ha sido visto como su conservadurismo. $\mathrm{Y}$ todas estas actitudes tienden, finalmente, a proteger el control colectivo - familiar y comunalde la tierra. Conservadurismo, por ejemplo, en tanto se resisten a obtener préstamos con garantía de la tierra. Y, claro, entonces, quedan fuera de los financiamientos capitalistas. Conservadurismo en las normas de respeto familiar: a nuestros ojos, la familia ampliada permite escasos márgenes de individualidad. Tal el caso de los matrimonios, que nosotros llamamos «arreglados»: las familias deliberan colectivamente acerca de los futuros contrayentes. Esto tiene también su explicación por su relación con el control de la tierra. Respecto de la contrayente, cabe la posibilidad de que el marido, quiera intervenir en el control de la tierra de su esposa, lo cual viola la regla de oro que es el control de la tierra exclusivamente por parte de la familia. Lo mismo sucede con la prohibición, que comienza a perder validez, de hacer heredar a las mujeres: cualquier participación de extraños en el control de la tierra, es visto con hostilidad en la familia. Estas prohibiciones, que nos causan asombro, se explican por la necesidad de conservar el control de la tierra en la forma de la no propiedad.

Estas prohibiciones se extienden a otras actividades comunitarias. Por ejemplo, respecto del control de los bienes muebles. Estos bienes, que no son la tierra, tienen distinto régimen jurídico según estén o no destinados a la producción. Así, pertenecen a la familia —quien 
habla de esas cosas con adjetivos posesivos, «nuestro»y «vuestro»—, sin que se puedan vender, las cosas destinadas al uso común, especialmente destinadas al trabajo agrario. Mientras que otras cosas, útiles pero no relacionadas directamente con la tarea agrícola, pueden ser enajenadas. Y cualquier similitud con las res mancipi y nec mancipi de los romanos, no es casualidad.

También son hostiles, las normas comunitarias, a todas las formas de la circulación mercantil, la existencia del dinero, y, mucho más, del préstamos a interés. También lo son a las formas capitalistas de la renta de la tierra: es palpable la prohibición del arrendamiento o la aparcería.

Por supuesto, en la medida en que triunfa la sociedad capitalista, las normas de la comunidad van siendo cada vez más desobedecidas, hasta que, en algún momento, la comunidad deja de usarlas y crea otras nuevas, éstas sí parecidas a las nuestras. Lo cual nos parece satisfactorio, pues «al fin los indios se van sumando al progreso».

Por otra parte, las comunidades, al menos las mexicanas, poseen otras normas, de «Derecho Público» diríamos nosotros. Son las normas que organizan el ejercicio del poder comunal. Por lo observado, principalmente por los antropólogos, las comunidades cuentan, si no todas, su amplia mayoría, de instituciones similares: una asamblea que dispone de todo el poder, y un cuerpo de funcionarios administrativos, judiciales y policiales, que rinden detallada cuenta de sus actividades. Esta organización política, ha recibido, por parte de los antropólogos, el extraño nombre de «sistema de cargos», con lo cual parecen querer expresar la diferencia que existe entre sus instituciones y las nuestras.

El nombre no parece adecuado, porque la sociedad capitalista también tiene un sistema de cargos. Sus funcionarios tienen «cargos», como los funcionarios de la comunidad. Sólo que, dicen, los de la comunidad no cobran salario alguno, y las normas ven con hostilidad cualquier aprovechamiento del cargo para algún beneficio personal. De modo que la diferencia parece recaer en el tema del salario: si no hay salario, es sistema de cargos. Si 
hay salario, es ... Como los antropólogos no estudian el Derecho moderno, no se ven obligados a hablar de ello.

Lo que resulta, a la observación de esta manera de mirar las instituciones comunitarias, es que, el hecho de que no cobren salario, es sólo la apariencia de un fenómeno que, así, queda en la penumbra. Lo que verdaderamente está en juego en la cuestión de la inexistencia del salario, es que las comunidades son sociedades de poder descentralizado; mientras que la nuestra es una sociedad de poder centralizado. Esto último significa que la sociedad distrae a algunos de sus miembros, de sus obligaciones productivas, y los especializa en «cumplir sus cargos». A cambio, les otorga un salario, que se paga con el aporte de los que sí producen. La comunidad no separa a nadie de su trabajo en la tierra, y por eso puede decirse que el poder es descentralizado: no lo monopoliza nadie, pues todos, al cabo del tiempo de su nombramiento, debe regresar al trabajo en la tierra. De modo que la gratuidad de los cargos en el «sistema de cargos», no es otra cosa que la prohibición de separarse del trabajo productivo; y éste consiste en su «diálogo» con la tierra. Con la no propiedad privada de la tierra.

Como puede comprenderse fácilmente, al no ser una sociedad fundada en la violencia, como la nuestra, se requiere, para su pervivencia, una adhesión emotiva «fuerte»; es decir, se requiere la firme convicción de parte de los comuneros, de que la comunidad es el camino recto de la vida social. Y esto se «materializa» en una enorme cantidad de normas cuyo objetivo es la construcción de esa ideología comunitaria que suele llamarse con la expresión de «sentimiento de pertenencia». Sin eso, el control de la tierra dejaría de ser colectivo; dejaría de tratarse de no propiedad. Y cuando eso sucede, cuanto comienza a desaparecer el «sentimiento de pertenencia» la comunidad se ha embarcado en el «progreso», y pronto la tierra dejará de ser controlada colectivamente. Contra eso luchan las comunidades. 


\section{BIBLIOGRAFÍA}

Engels, Federico, 2000, El origen de la familia, la propiedad privada y el Estado. 1. ${ }^{\mathrm{a}}$ edición 1884. Editorial Espartaco, Moscú.

Kelsen, Hans, 1988, Teoría General del Derecho y del Estado. UNAM, México.

Marx, Karl, 1978, El Capital. Siglo XXI, México.

Vélez Sársfield, Dalmacio, 1869, Proyecto de Código Civil Argentino. Imp. de la Nación, 4 tomos en 5 volúmenes, Buenos Aires.

Weber, Max, 1997, Economía y Sociedad. FCE, México

\section{Notas*}

${ }^{1}$ Rojina Villegas, Rafael, 2000, Derecho Civil Mexicano. P. 289. Porrúa, México. Tomo esta cita de Arratíbel Salas y Francisco José Huber Olea, Código Civil para el Distrito Federal. T. 1, p. 572. Sista, México.

${ }^{2}$ Nótese que el código mexicano hace lo mismo que el francés.

${ }^{3}$ Esto está dicho como si los argentinos no tuvieran también que ocultar el origen de sus propiedades robadas a los indígenas.

${ }^{4}$ Permítaseme remitirme a Correas, Óscar, 2000, Introducción a la Crítica del Derecho Moderno. (Esbozo.) Capítulo 6, pp. 95 y ss. Fontamara, México.

* Se respetó el original del autor

Fecha de recepción: 18 de septiembre de 2007.

Fecha de aceptación: 31 de octubre de 2007. 